\title{
Associations of perceived daily walking duration with residential food outlets in small Chinese cities: a cross-sectional study
}

\section{Ziwen Sun ( $\nabla$ Ziwen.Sun@ed.ac.uk)}

The University of Edinburgh https://orcid.org/0000-0002-1900-4648

lain Scott

The University of Edinburgh

\section{Simon Bell}

The University of Edinburgh

\section{Xiaomeng Zhang}

The University of Edinburgh

\section{Lan Wang}

Tongji University

\section{Research}

Keywords: food environment diversity, food outlets, walking, street vending, neighborhood, adults, agerelated differences, Chinese urban contexts

Posted Date: August 11th, 2020

DOI: https://doi.org/10.21203/rs.3.rs-54597/v1

License: (c) (i) This work is licensed under a Creative Commons Attribution 4.0 International License.

Read Full License 


\section{Abstract}

Background: The impact of food outlets (particularly those trading in fast food) on weight gain has been evidenced by numerous studies, but the potential health benefits of these amenities have received less attention. This study aims to examine the associations between residential food environments and perceived daily walking duration (DailyWalk) in small Chinese cities.

Methods: The study draws upon two interviewer-administered questionnaire surveys $(n=354)$ conducted in Yuncheng and Suihua between 2017-2018. Logistic regression models were used to examine the associations of DailyWalk (i.e. $>60$ minutes and $\leq 60$ minutes per day) with seven different typologies of food outlet (i.e. market, fruit/vegetable street vending, snack/breakfast street vending, grocery store, supermarket, restaurant and café/tea house) at three levels of walking distance (i.e. 1-5 minutes, 6-10 minutes and over 10 minutes). The associations were further explored through two different age groups (i.e. 18-35 and 36-59) and by food environment diversity.

Results: With the exception of café/tea house, the other six food amenities were positively associated with DailyWalk. After adjusting for socio-economic variables, the associations of grocery store and supermarket weakened. Higher levels of food environment diversity were associated with a longer DailyWalk. Among the two age groups studied, food outlets were more associated with older adults' DailyWalk.

Conclusions: Our study provides the first quantitative investigation of the walking benefits of food outlets including informal street vendors in small Chinese cities. These findings can help urban designers and policy makers to increase physical activity and create a healthy living environment.

\section{Introduction}

Globally, increasing physical activity (PA) has become an ever more significant topic for both research and practice due to its positive outcomes (e.g. increasing PA to reduce non-communicable diseases and promote mental health among young people, promoting encounter opportunities to facilitate social relations, and reducing vehicle exhaust fumes)[1-4]. Numerous studies have proven that PA is associated with walkable environmental factors, such as land-use mix, accessibility, high residential density, street connectivity and pedestrian-oriented design [5-10]. However, most studies that examine the role of neighbourhood destinations in PA have used destination measures, assuming that all destinations matter equally in the promotion of PA $[11,12]$, and this has overlooked the nuanced associations of PA with different amenity types.

For example, certain recreational areas in a neighbourhood, such as urban park and blue space, have been positively related to PA and mental health, while it has been revealed that other such amenities (e.g. karaoke bar and cinema) might in fact play a negative role in generating walking behaviours [13-16]. Furthermore, different age groups might have different demands for the same amenities, leading to different associations of PA to the same neighbourhood environment [15-19]. Therefore, we contend that 
before using land-use mix as a whole, different amenities need to be separately analysed in relation to their different functions and demands in local contexts.

Many studies have indicated a functional amenity, which have examined associations of neighbourhood food outlets with a series of outcomes, such as mortality [20], body mass index/obesity [21-23], unhealthy eating habits [24,25], age-related differences [23, 26], socioeconomic status [21, 27], neighbourhood characteristics (e.g. school, work site or home) [27] and food intakes/purchase motivations [28-30]. Among different food-related outlets, a higher prevalence of obesity was found in areas that had small grocery stores or fast food providers, while lower in areas with supermarkets and fruit/vegetable providers [21, 22, 26, 31]. Sevtsuk et al. (2014) explained that the nearby presence of food outlets could constitute an important aspect of liveable and walkable neighbourhood environments, potentially increasing transport-related PA [32]. However, only a few studies have examined the nuanced relations between proximity of different food outlets and PA in a neighbourhood [12,30,32], and little of the empirical evidence has been gathered in Chinese cities [10,33].

Recent studies have demonstrated that due to the different context of Chinese cities (e.g. unprecedented speed of urban development, high-density sprawl and informality), some associations of PA with walkable environmental factors such as land-use mix and high residential density are ineffective or even counterproductive $[15,34-36]$. This means that in applying western theories and methods to the study of walkability in China, some previously validated factors need to be re-examined and disassembled.

Additionally, most Chinese studies on urban issues have concentrated on large cities, with issues in small cities being largely under-represented [37,38]. Due to factors in large cities such as better public transport infrastructure and higher levels of educational attainment [1,39], neighbourhood environment impact on patterns of PA is likely to be different in small cities.

The aim of this study, therefore, is to examine associations of PA with neighbourhood food outlets in small Chinese cities. We consider perceived daily walking duration (DailyWalk) as physical activity. The term DailyWalk in this context as a perceived distance rather than an actual measured distance. Moreover, given the known differences in the role of Chinese neighbourhood environment on walking behaviours by age, these associations are further explored through two age groups.

\section{Methods}

Details of the definition of small Chinese cities are given elsewhere [15]. In short, according to the most recent Chinese census, the number of inhabitants in each of these two cities is around 5 million, and when Chinese cities are categorised via their urban population, $42.4 \%$ of the population of the entire country is shown to live in cities of 4 to 8 million $[40,41]$. The vast majority of the Chinese people are living in small and medium-sized cities. Based on the Chinese city ranking carried out by China Business Network Co. Ltd, the selected cities (Yuncheng and Suihua) belong to Tiers 4 and 5 out of five tiers [42]. This means that they are both small and are of the type that is commonplace and ordinary in China. Both cities are the prefecture-level municipality and have only one central district - in Yuncheng this is Yanhu district and in Suihua, Beilin district. 
The questionnaire surveys were conducted in the streets of the cities' two central districts, in August 2017 (Yanhu) and June 2018 (Beilin), as people generally spend more time outdoors during warmer weather. Seven volunteers in Yuncheng were recruited from Yuncheng University and six volunteers in Suihua were recruited from the local urban planning department for the interviewer-administered approach. Volunteers attempted to ask every person on the city centre streets, although many busy pedestrians refused to participate in this survey. This research was approved by the ECA Ethics Committee at the University of Edinburgh (No. 06032017).

The questionnaire content with detailed items has been presented in another study [15], adapted from the Neighbourhood Environment Walkability Scale [43]. We extracted three key subscales in accordance with the aim of this study, including perceived daily walking duration as the single outcome variable (i.e. DailyWalk) and seven types of food outlet (i.e. fruit/vegetable market, fruit/vegetable street vending, snack/breakfast street vending, convenience/small grocery store, supermarket, restaurant and café/tea house). The third subscale included a range of socioeconomic characteristics: gender, age, educational attainment (junior college or lower and bachelor's degree or higher), family income (3,000 Yuan or less, $3,001-5,000$ and 5,001+) and occupation (employed, self-employed and other). During the pilot study in January 2017 , food outlets used in western studies $[21,43]$ were adapted to the local contexts, such as street vendors and café/tea houses. A few studies in China noted that street vending could be an interesting factor to examine walkability [44-46].

We aimed to collect 200 questionnaires in each city, because the sample size of most previous studies on environment walkability was between 101 and 300 [47]. All data were carefully checked via a datacleaning process [48]. The original datasets had 183 participants in Yuncheng and 195 in Suihua. After removing participants with missing walking duration $(n=2)$, missing age group $(n=1)$, missing education $(n=2)$ and missing family income $(n=1)$, and those aged under 18/over $60(n=18)$, the final datasets for analysis had 171 participants in Yuncheng and 183 in Suihua. Because of the small non-representative samples, we combined the two datasets $(n=354)$ and the city became an additional variable, which enabled regressions to be performed more feasibly.

First, we categorised DailyWalk into two levels - greater than 60 minutes and equal to or less than 60 minutes - due to the recommended daily PA being at least 60 minutes $[12,49]$. The walking distances to each amenity were categorised as 1-5 minutes, 6-10 minutes, over 10 minutes and missing. "Missing" indicates "I do not know where the amenity is". Stata 15 software was used to analyse the pooled dataset. We performed univariate and multivariate logistic regression to detect the associations between DailyWalk and the seven food outlet factors respectively. For the multivariate logistic regression model, we adjusted for city (Yuncheng and Suihua), gender, age, educational attainment, family income and occupation.

Secondly, to further understand the impact of food outlets on DailyWalk among different age groups, participants were categorised into younger adults (aged 18-35) and older adults (aged 36-59). This threshold was the same as that used in previous studies in Chinese contexts $[15,50]$. We then performed the multivariate logistic regression model for the two age groups. Finally, using logistic regression, we examined the associations of DailyWalk with three levels of food environment diversity, in line with the 
analysis approach[8]. We set three $P$ value thresholds of $P \leq 0.001, P \leq 0.01$ and $P \leq 0.05$ for the detector sensitivity. Additionally, linear regression was performed as a sensitivity analysis by using the average walking duration on each scale to avoid bias introduced by information loss.

\section{Results}

In the pooled data, $48.31 \%$ of participants lived in Yuncheng, $51.69 \%$ were male, $52.82 \%$ were $18-35$ years old, $78.25 \%$ had graduated from no higher than junior college (junior college is a post-high school option for people who cannot meet university entry requirements), $42.09 \%$ were employed and $36.72 \%$ were "other" (i.e. unemployed or students) (Table 1). Table 2 shows that more than $79 \%$ of participants were able to access a market, fruit/vegetable street vending, snack/breakfast street vending and a grocery store within 10 minutes' walk. Supermarkets, restaurants and cafés/tea houses were relatively sporadic in the neighbourhood; fewer than $73 \%$ of participants could access them within 10 minutes' walk. Of the seven food amenities, only café/tea house had a relatively high missing value, with $24 \%$ of participants not knowing where the amenity was. 
Table 1

Descriptive analysis of sociodemographic characteristics $(\mathrm{N}=354)$.

\begin{tabular}{|c|c|c|}
\hline & \multicolumn{2}{|l|}{ All } \\
\hline & $\mathrm{N}$ & $\%$ \\
\hline \multicolumn{3}{|l|}{ City } \\
\hline Yuncheng & 171 & 48.31 \\
\hline Suihua & 183 & 51.69 \\
\hline \multicolumn{3}{|l|}{ Gender } \\
\hline Male & 183 & 51.69 \\
\hline Female & 171 & 48.31 \\
\hline \multicolumn{3}{|l|}{ Age groups } \\
\hline $18-35$ & 187 & 52.82 \\
\hline $36-59$ & 167 & 47.18 \\
\hline \multicolumn{3}{|l|}{ Educational attainment } \\
\hline Junior College or below & 277 & 78.25 \\
\hline Bachelor or higher & 77 & 21.75 \\
\hline \multicolumn{3}{|l|}{ Occupation } \\
\hline Employed & 149 & 42.09 \\
\hline Self-employed & 75 & 21.19 \\
\hline Others & 130 & 36.72 \\
\hline \multicolumn{3}{|c|}{ Family income (Chinese Yuan) } \\
\hline 3,000 or below & 80 & 22.60 \\
\hline $3,001-5,000$ & 131 & 37.01 \\
\hline $5,001+$ & 143 & 40.40 \\
\hline
\end{tabular}

\section{Univariate logistic regression}

The univariate logistic regression produced associations between the seven food environment factors and DailyWalk (Table 2), with the association of café/tea house being relatively weak.

Market, fruit/vegetable street vending, snack/breakfast street vending, grocery store, supermarket and restaurant were strongly $(P \leq 0.001)$ related to a longer DailyWalk for people who could access these food 
outlets in 1-5 minutes compared with those who took more than 10 minutes. The odds ratio (OR) and 95\% confidence interval (Cl) were 4.69 (2.37-9.28), 3.28 (1.70-6.32), 7.12 (3.21-15.75), 6.07 (2.48$14.88), 4.09$ (2.31-7.24) and $4.96(2.80-8.78)$ respectively. Only market and restaurant were strongly $(\mathrm{P} \leq$ 0.001 ) related to a longer DailyWalk for people who could access these food outlets in 6-10 minutes compared with those who took more than 10 minutes. The OR and $95 \% \mathrm{Cl}$ were $3.56(1.68-7.53)$ and 4.46 (2.35-8.48) respectively. In contrast, for café/tea house, only people who lived 6-10 minutes' walk away reported a longer DailyWalk, compared with those who lived more than 10 minutes' walk away (OR [95\%Cl]: $2.05[1.08-3.90], \mathrm{P} \leq 0.05)$. 
Table 2

Logistic regression analysis for the associations between residential food environment variables and perceived daily walking duration $(\mathrm{N}=354)$.

\section{Perceived daily walking duration ${ }^{\mathrm{a}}$}

\begin{tabular}{|c|c|c|c|c|}
\hline$N$ & & Univariate & & Multivariate $^{\mathrm{b}}$ \\
\hline 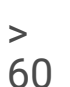 & $<=60$ & OR $(95 \% \mathrm{Cl})$ & $\mathrm{p}$-value & OR $(95 \% \mathrm{Cl})$ \\
\hline
\end{tabular}

(Fruit/vegetable) market

\begin{tabular}{|c|c|c|c|c|c|c|}
\hline $1-5$ minutes & 91 & 97 & $\begin{array}{l}4.69(2.37- \\
9.28)\end{array}$ & $0.000 * *$ & $\begin{array}{l}3.42(1.65- \\
7.08)\end{array}$ & 0.001 ** \\
\hline $6-10$ minutes & 37 & 52 & $\begin{array}{l}3.56(1.68- \\
7.53)\end{array}$ & $0.001^{* *}$ & $\begin{array}{l}3.33(1.50- \\
7.36)\end{array}$ & $0.003^{* *}$ \\
\hline$>10$ minutes & 12 & 60 & 1 & & 1 & \\
\hline Missing & 1 & 4 & & & & \\
\hline \multicolumn{7}{|c|}{$\begin{array}{l}\text { Fruit/vegetable street } \\
\text { vending }\end{array}$} \\
\hline $1-5$ minutes & 91 & 101 & $\begin{array}{l}3.28(1.70- \\
6.32)\end{array}$ & $0.000 * *$ & $\begin{array}{l}2.90(1.43- \\
5.87)\end{array}$ & $0.003^{* *}$ \\
\hline $6-10$ minutes & 36 & 60 & $\begin{array}{l}2.19(1.06- \\
4.50)\end{array}$ & $0.034^{\star}$ & $\begin{array}{l}2.37(1.09- \\
5.14)\end{array}$ & $0.029 *$ \\
\hline$>10$ minutes & 14 & 51 & 1 & & 1 & \\
\hline Missing & 0 & 1 & & & & \\
\hline \multicolumn{7}{|c|}{$\begin{array}{l}\text { Snack/breakfast street } \\
\text { vending }\end{array}$} \\
\hline $1-5$ minutes & 104 & 95 & $\begin{array}{l}7.12(3.21- \\
15.75)\end{array}$ & $0.000 * *$ & $\begin{array}{l}5.25(2.25- \\
12.22)\end{array}$ & $0.000 * *$ \\
\hline $6-10$ minutes & 27 & 62 & $\begin{array}{l}2.83(1.18- \\
6.76)\end{array}$ & $0.019 *$ & $\begin{array}{l}3.41(1.36- \\
8.55)\end{array}$ & $0.009 * *$ \\
\hline$>10$ minutes & 8 & 52 & 1 & & 1 & \\
\hline
\end{tabular}

OR: odds ratio; $\mathrm{Cl}$ : confidence interval.

${ }^{a}>60$ minutes versus $<=60$ minutes (referent).

${ }^{b}$ Analyses adjusted for city (Yuncheng, Suihua), gender (male, female), age groups (18-35, 36-59), education attainment (junior college or below, bachelor or higher), household income $(3,000$ or below, $3,001-5,000,5,001+)$, occupation (employed, self-employed, others).

* $p \leq 0.05$, ** $p \leq 0.01$, ** $p \leq 0.001$ 


\section{Perceived daily walking duration $^{a}$}

Missing 24

(Convenience/small) grocery store

$\begin{array}{lllllll}1-5 \text { minutes } & 113 & 121 & \begin{array}{l}6.07(2.48- \\ 14.88)\end{array} & 0.000 * * & \begin{array}{l}4.67(1.80- \\ 12.08)\end{array} & 0.001 * * \\ \text { 6-10 minutes } & 22 & 53 & \begin{array}{l}2.70(1.00- \\ 7.28)\end{array} & 0.050 * & \begin{array}{l}2.12(0.74- \\ 6.07)\end{array} & 0.159 \\ & & & & & \end{array}$

$>10$ minutes

$\begin{array}{lll}6 & 39 & 1\end{array}$

1

Missing

$0 \quad 0$

Supermarket

$\begin{array}{lccllll}1-5 \text { minutes } & 90 & 87 & \begin{array}{l}4.09(2.31- \\ 7.24)\end{array} & 0.000 * * & 2.30(1.17- & 0.016^{*} \\ \text { 6-10 minutes } & 31 & 46 & \begin{array}{l}2.66(1.36- \\ 5.20)\end{array} & 0.004 * * & 2.04(0.99- & 0.054 \\ & & & & 4.22) & \\ >10 \text { minutes } & 20 & 79 & 1 & 1 & \\ \text { Missing } & 0 & 1 & & & & \end{array}$

Restaurant

1-5 minutes

$77 \quad 71$

$4.96(2.80-$

8.78)

$0.000 * * 3.52(1.87-$

$0.000 * *$

6-10 minutes

$40 \quad 41$

$4.46(2.35-$

8.48)

$6.64)$

(10 minutes

$\begin{array}{lll}21 & 96 & 1\end{array}$

$\begin{array}{ll}0.000 * * & 3.87(1.95- \\ & 7.66)\end{array}$

$0.000 * *$

$>10$ minutes

35

Missing 5

Café/tea house

$1-5$ minutes

$18 \quad 19$

$2.03(0.99-$

4.14)

0.053

$1.45(0.65-$

$3.21)$

6-10 minutes

$24 \quad 25$

$2.05(1.08-$
$3.90)$

$0.028^{*}$

$1.44(0.70-$ 2.96)

OR: odds ratio; $\mathrm{Cl}$ : confidence interval.

${ }^{a}>60$ minutes versus $<=60$ minutes (referent).

${ }^{b}$ Analyses adjusted for city (Yuncheng, Suihua), gender (male, female), age groups (18-35, 36-59), education attainment (junior college or below, bachelor or higher), household income $(3,000$ or below, $3,001-5,000,5,001+)$, occupation (employed, self-employed, others).

* $p \leq 0.05, * * p \leq 0.01, * * p \leq 0.001$ 


\section{Perceived daily walking duration ${ }^{a}$}

$\begin{array}{lllll}>10 \text { minutes } & 58 & 124 & 1 & 1 \\ \text { Missing } & 41 & 45 & \end{array}$

OR: odds ratio; Cl: confidence interval.

${ }^{a}>60$ minutes versus $<=60$ minutes (referent).

${ }^{\mathrm{b}}$ Analyses adjusted for city (Yuncheng, Suihua), gender (male, female), age groups (18-35, 36-59), education attainment (junior college or below, bachelor or higher), household income $(3,000$ or below, $3,001-5,000,5,001+$ ), occupation (employed, self-employed, others).

${ }^{*} p \leq 0.05,{ }^{* *} p \leq 0.01, * * p \leq 0.001$

\section{Multivariate logistic regression}

After adjusting for six potential confounding factors, a longer DailyWalk for people who could access the food outlets except for café/tea house in 1-5 minutes compared with those who took more than 10 minutes still exist with a decreased effect estimate (Table 2). The OR and $95 \% \mathrm{Cl}$ were $3.42(1.65-7.08)$, 2.90 (1.43-5.87), 5.25 (2.25-12.22), 4.67 (1.80-12.08), 2.30 (1.17-4.51), 3.52 (1.87-6.64) for the market, fruit/vegetable street vending, snack/breakfast street vending, grocery store, supermarket and restaurant respectively. People can access market, fruit/vegetable street vending, snack/breakfast street vending and restaurant within 6-10 minutes remain to have a longer DailyWalk compared to those can access these food outlets more than 10 minutes. But for the grocery store, supermarket and café/tea house, the effect disappeared after the adjustment for a distance equal to 6-10 minutes' walk (compared with more than 10 minutes' walk). The results of the sensitivity analyses were consistent with the results of the univariate and multivariate logistic regressions (Supplementary Table 1). 
Table 3

Logistic regression analysis for the associations between residential food environment variables and perceived daily walking duration by age groups $(\mathrm{N}=354)$.

\section{Perceived daily walking duration*}

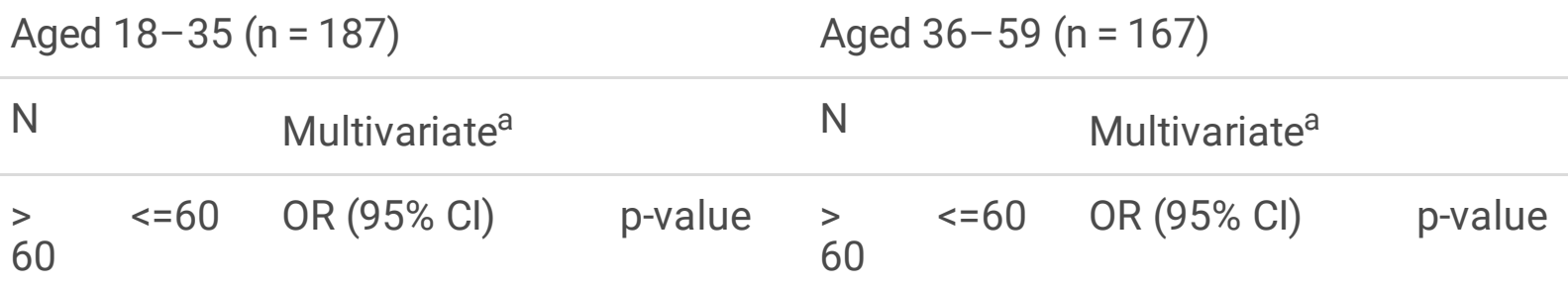

(Fruit/vegetable) market

$\begin{array}{lccllllll}1-5 \text { minutes } & 38 & 55 & \begin{array}{l}3.22(1.08- \\ 9.59)\end{array} & 0.036^{*} & 53 & 42 & \begin{array}{l}3.78(1.39- \\ 10.33)\end{array} & 0.009 * * \\ \begin{array}{l}\text { 6-10 } \\ \text { minutes }\end{array} & 18 & 32 & \begin{array}{l}3.44(1.05- \\ 11.32)\end{array} & 0.042^{*} & 19 & 20 & \begin{array}{l}3.12(1.04- \\ 9.30)\end{array} & 0.041^{*} \\ >10 \text { minutes } & 5 & 35 & 1 & & 7 & 25 & 1 & \\ \text { Missing } & 1 & 3 & & 0 & 1 & & \end{array}$

Fruit/vegetable street vending

\begin{tabular}{lllllllll}
$1-5$ minutes & 40 & 62 & $\begin{array}{l}2.71(0.90- \\
8.21)\end{array}$ & 0.078 & 51 & 39 & $\begin{array}{l}3.22(1.25- \\
8.27)\end{array}$ & $0.015^{*}$ \\
& & & & & & \\
\hline $\begin{array}{l}6-10 \\
\text { minutes }\end{array}$ & 17 & 33 & $\begin{array}{l}2.79(0.83- \\
9.35)\end{array}$ & 0.097 & 19 & 27 & $\begin{array}{l}1.90(0.66- \\
5.47)\end{array}$ & 0.232 \\
\hline
\end{tabular}

$\begin{array}{lllllll}>10 \text { minutes } & 5 & 29 & 1 & 9 & 22 & 1 \\ \text { Missing } & 0 & 1 & & 0 & 0 & \end{array}$

Snack/breakfast street vending

$\begin{array}{lllllllll}1-5 \text { minutes } & 46 & 52 & \begin{array}{l}7.13(1.51- \\ 33.56)\end{array} & 0.013^{*} & 58 & 43 & \begin{array}{l}5.24(1.77- \\ 15.51)\end{array} & 0.003^{\star *} \\ & & & & & & \end{array}$

$\begin{array}{lllllllll}\begin{array}{l}6-10 \\ \text { minutes }\end{array} & 14 & 44 & \begin{array}{l}4.63(0.92- \\ 23.31)\end{array} & 0.063 & 13 & 18 & \begin{array}{l}2.88(0.86- \\ 9.57)\end{array} & 0.085 \\ & & & & & \end{array}$

$\begin{array}{lllllll}>10 \text { minutes } & 2 & 26 & 1 & 6 & 26 & 1\end{array}$

OR: odds ratio; Cl: confidence interval.

${ }^{a}>60$ minutes versus $<=60$ minutes (referent).

${ }^{b}$ Analyses adjusted for city (Yuncheng, Suihua), gender (male, female), age groups (18-35, 36-59), education attainment (junior college or below, bachelor or higher), household income $(3,000$ or below, $3,001-5,000,5,001+$ ), occupation (employed, self-employed, others).

* $p \leq 0.05, * \star p \leq 0.01, * * p \leq 0.001$ 


\section{Perceived daily walking duration*}

\begin{tabular}{|c|c|c|c|c|c|c|c|c|}
\hline Missing & 0 & 3 & & & 2 & 1 & & \\
\hline \multicolumn{9}{|c|}{ (Convenience/small) grocery store } \\
\hline $1-5$ minutes & 49 & 66 & $\begin{array}{l}6.45(1.34- \\
30.93)\end{array}$ & $0.020 *$ & 64 & 55 & $\begin{array}{l}3.71(1.08- \\
12.81)\end{array}$ & $0.038^{*}$ \\
\hline $\begin{array}{l}6-10 \\
\text { minutes }\end{array}$ & 11 & 36 & $\begin{array}{l}2.35(0.43- \\
12.80)\end{array}$ & 0.322 & 11 & 17 & $\begin{array}{l}1.90(0.47- \\
7.73)\end{array}$ & 0.368 \\
\hline$>10$ minutes & 2 & 23 & 1 & & 4 & 16 & 1 & \\
\hline Missing & 0 & 0 & & & 0 & 0 & & \\
\hline \multicolumn{9}{|l|}{ Supermarket } \\
\hline $1-5$ minutes & 37 & 45 & $\begin{array}{l}1.98(0.75- \\
5.22)\end{array}$ & 0.169 & 53 & 42 & $\begin{array}{l}2.90(1.09- \\
7.74)\end{array}$ & $0.034^{\star}$ \\
\hline $\begin{array}{l}6-10 \\
\text { minutes }\end{array}$ & 16 & 33 & $\begin{array}{l}1.48(0.53- \\
4.10)\end{array}$ & 0.455 & 15 & 13 & $\begin{array}{l}3.11(1.06- \\
9.08)\end{array}$ & $0.038^{*}$ \\
\hline$>10$ minutes & 9 & 46 & 1 & & 11 & 33 & 1 & \\
\hline Missing & 0 & 1 & & & 0 & 0 & & \\
\hline \multicolumn{9}{|l|}{ Restaurant } \\
\hline $1-5$ minutes & 35 & 37 & $\begin{array}{l}4.79(1.88- \\
12.16)\end{array}$ & $0.001 * *$ & 42 & 34 & $\begin{array}{l}3.08(1.19- \\
7.96)\end{array}$ & $0.020 *$ \\
\hline $\begin{array}{l}6-10 \\
\text { minutes }\end{array}$ & 18 & 27 & $\begin{array}{l}4.37(1.57- \\
12.13)\end{array}$ & $0.005^{\star *}$ & 22 & 14 & $\begin{array}{l}3.88(1.45- \\
10.37)\end{array}$ & $0.007 * \star$ \\
\hline$>10$ minutes & 8 & 58 & 1 & & 13 & 38 & 1 & \\
\hline Missing & 1 & 3 & & & 2 & 2 & & \\
\hline \multicolumn{9}{|l|}{$\begin{array}{l}\text { Café/tea } \\
\text { house }\end{array}$} \\
\hline $1-5$ minutes & 10 & 11 & $\begin{array}{l}1.93(0.62- \\
5.97)\end{array}$ & 0.253 & 8 & 8 & $\begin{array}{l}0.88(0.27- \\
2.92)\end{array}$ & 0.834 \\
\hline
\end{tabular}

OR: odds ratio; $\mathrm{Cl}$ : confidence interval.

$\mathrm{a}_{>}>60$ minutes versus $<=60$ minutes (referent).

${ }^{b}$ Analyses adjusted for city (Yuncheng, Suihua), gender (male, female), age groups (18-35, 36-59), education attainment (junior college or below, bachelor or higher), household income $(3,000$ or below, $3,001-5,000,5,001+$ ), occupation (employed, self-employed, others).

$* p \leq 0.05, * * p \leq 0.01, * * p \leq 0.001$ 


\begin{tabular}{|c|c|c|c|c|c|c|c|c|}
\hline \multirow[b]{2}{*}{$\begin{array}{l}6-10 \\
\text { minutes }\end{array}$} & \multicolumn{8}{|c|}{ Perceived daily walking duration* } \\
\hline & 15 & 13 & $\begin{array}{l}2.31(0.83- \\
6.41)\end{array}$ & 0.107 & 9 & 12 & $\begin{array}{l}0.91(0.32- \\
2.64)\end{array}$ & 0.867 \\
\hline$>10$ minutes & 26 & 75 & 1 & & 32 & 49 & 1 & \\
\hline Missing & 11 & 26 & & & 30 & 19 & & \\
\hline \multicolumn{9}{|c|}{ OR: odds ratio; Cl: confidence interval. } \\
\hline \multicolumn{9}{|c|}{ a $>60$ minutes versus $<=60$ minutes (referent). } \\
\hline \multicolumn{9}{|c|}{$\begin{array}{l}\text { bAnalyses adjusted for city (Yuncheng, Suihua), gender (male, female), age groups }(18-35,36-59) \text {, } \\
\text { education attainment (junior college or below, bachelor or higher), household income }(3,000 \text { or below, } \\
3,001-5,000,5,001+) \text {, occupation (employed, self-employed, others). }\end{array}$} \\
\hline
\end{tabular}

\section{Age-stratified logistic regression}

The results of this subgroup analysis are shown in Table 3. Café/tea house was not associated with DailyWalk in any age group. For people aged 18-35, living 1-5 and 6-10 minutes away from market and restaurant had a longer DailyWalk compared with living more than 10 minutes away $(\mathrm{OR}[95 \% \mathrm{Cl}]: 3.22$ [1.08-9.59]/3.44 [1.05-11.32] and 4.79 [1.88-12.16]/4.37 [1.57-12.13]. Living 1-5 minutes away from snack/breakfast street vending and grocery store had also influenced their DailyWalk. For people aged 36-59, DailyWalk was potentially influenced by most of the food outlet locations and the effect estimates, apart from fruit/vegetable street vending, snack/breakfast street vending and grocery store for 6-10 minutes away.

\section{Food environment diversity}

We generated the diversity of residential food outlets by calculating the mean walking time to the seven food outlets (Table 4). A total of 119 participants have a tertile-3 (4.57-5.00), 135 participants have a tertile-2 (3.71-4.43) and 100 participants have a tertile-1 (1.71-3.57). The higher the tertile, the greater the diversity of residential food outlets. Compared with tertile-1, tertile-3 and tertile-2 associated with a longer DailyWalk, the ORs $(95 \% \mathrm{Cl})$ were $3.79(2.16-6.63)$ and $4.12(2.27-7.47)$ respectively in the univariate model and $3.12(1.61-6.04)$ and $2.91(1.59-5.33)$ respectively in the multivariate model. 
Table 4

Logistic regression analysis for the association between the diversity of residential food environment variables and perceived daily walking duration $(\mathrm{N}=354)$.

\section{Perceived daily walking duration}

\begin{tabular}{|c|c|c|c|c|}
\hline$N$ & & Unadjusted & & Adjusted $^{a}$ \\
\hline$>60$ & $<=60$ & OR $(95 \% \mathrm{Cl})$ & $\mathrm{p}$-value & OR $(95 \% \mathrm{Cl})$ \\
\hline
\end{tabular}

Diversity of residential food constructs ${ }^{b}$

$\begin{array}{lllllll}\text { Tertile 3 (4.57-5.00) } & 24 & 95 & 3.79(2.16-6.63) & 0.000 & 3.12(1.61-6.04) & 0.001\end{array}$

$\begin{array}{lllllll}\text { Tertile 2(3.71-4.43) } & 66 & 69 & 4.12(2.27-7.47) & 0.000 & 2.91(1.59-5.33) & 0.001\end{array}$

$\begin{array}{lllll}\text { Tertile } 1(1.71-3.57) & 51 & 49 & 1 & 1\end{array}$

Note. OR: odds ratio; Cl: confidence interval.

${ }^{a}$ Analyses adjusted for city (Yuncheng, Suihua), gender (male, female), age groups (18-35, 36-59), education attainment (junior college or below, bachelor or higher), household income $(3,000$ or below, $3,001-5,000,5,001+$ ), occupation (employed, self-employed, others).

${ }^{b}$ Diversity of residential food constructs $=$ mean of the seven food items $(5=1-5$ minutes; $4=6-10$ minutes; $3=11-20$ minutes; $2=21-30$ minutes; $1=31+$ minutes and don't know). A "don't know" response is also coded as " 1 " because the walking distance to an unaware amenity is likely more than 31 minutes.

\section{Discussion}

Studies on neighbourhood food environments have often focused on obesity or body mass index issues, while research on physical activity has considered food outlets as a category for land-use mix. In this study, we examined the associations between DailyWalk and seven typologies of food outlet, taking into account two age groups and three levels of food environment diversity. To our knowledge, and based on a review about environmental correlates of physical activity in China [10], this study constitutes the first quantitative investigation of the walking benefits of food outlets in small Chinese cities. Walking is one of the most common physical activities across all groups, regardless of social class, gender or age [1,36], so much so that perceived daily walking duration is generally considered a proxy of physical activity in the below discussion.

\section{Associations between food environments and physical activity}

Our findings indicate that, apart from café/tea house, the other six food amenities within a short walking distance from home are meaningful predictors of PA, and that these associations are generally upheld after adjusting for a series of covariates. This suggests that the importance of the availability of neighbourhood food outlets as an opportunity to increase PA in small Chinese cities is in line with that 
revealed by previous studies $[12,33]$. A potential explanation is that walking distance to the grocery store, supermarket and restaurant is associated with food purchasing, meaning that a shorter walking distance has a higher purchasing motivation [30]. This motivation potentially produces higher-frequency of transport-related walking within a neighbourhood.

Notably, the weak association of café/tea house suggests a walking destination for low-frequency recreation with higher consumption. Through field observation in both cities, café houses engaged with younger adults and school children playing mobile phone games or doing homework together, and tea houses attracted groups of people playing mah-jong. Foods had a higher price as optional snacks in café/tea houses, compared with those in other food outlets. Café/tea house naturally belongs to recreational amenities (e.g. karaoke bar) in small Chinese cities that generate higher profits and tend to be located together to facilitate competitiveness, while at the same time not being relevant to regular, basic everyday demands, leading to the non-association of PA [15]. However, an unexpected association of café/tea house became stronger if the duration was 6-10 minutes' walk from home, compared with a duration of 5 minutes' walk. This indicates that the associations between walking distance to food outlets and PA do not always adhere to the principle that shorter is better, leading to a critical understanding of the popular attenuation algorithm on walkability [6]. People might occasionally enjoy walking to a café/tea house within walking distance but if it is too close to home other high-demand amenities and necessary activities might be replaced by this more superfluous and recreational amenity. Future studies should examine the nuanced associations of DailyWalk with individual food outlets in relation to different demands and motivations.

In general, participants who walked for more than 60 minutes per day reported less frequently the option "I do not know where the amenity is" (i.e. the "missing" item in Table 2). This suggests that higher DailyWalk levels can make people more aware of their neighbourhood amenities and, in turn, this awareness might increase their walking motivation and frequency. In addition, more than half of the participants reported a walking distance from home of within 10 minutes to fruit/vegetable and snack/breakfast street vendors, and these two mobile amenity providers were positively associated with DailyWalk. This contributes empirical evidence to the conceptual discussion about the emergence of street vending as a mobile amenity in many residential neighbourhoods in China, increasing the land-use mix and potentially having an impact on walking behaviour $[38,44,45]$. This finding suggests that although street vendors might sell unhealthy food and be loosely controlled by local authorities, they can closely engage with common everyday lives and increase PA in small Chinese cities.

\section{Socioeconomic factors}

The effect of the built environment on walking behaviour might be varied by socioeconomic factors [5]. After adjustment, most associations in our study still existed, particularly for market, fruit/vegetable street vending, snack/breakfast street vending and restaurant. This means that these four food outlets are important destinations within residential neighbourhoods, and that they are likely to increase PA for all. In addition, the weak association of café/tea house disappeared, and the associations of supermarket and grocery store became weaker. This reveals that these three outlet types are more variously impacted by 
different socioeconomic groups. One speculation is that migrants and older people in China prefer to purchase from informal street vendors or markets due to the lower prices, compared with purchasing in supermarkets and grocery stores $[15,50]$. Our field observation revealed that grocery stores often occurred inside residential buildings at an extremely short distance from home, but the price of fruit and vegetables in these amenities was much higher than when bought from street vendors or in markets, partly due to higher rental costs. Thus, a trade-off is that walking more can expend less money on a similar produce. Future research that examines the association of consumption levels of different food outlets with PA is necessary.

\section{Age groups}

Other studies have indicated that older people are likely to be affected by the neighbourhood environment due to the fact that their bodies are ageing and their time considerably more flexible $[18,19]$. For this reason, the associations of DailyWalk for older adults in our study were stronger and more diverse than those for younger adults. A recent study notes that the strongest association with adolescents' PA is grocery store [12]. We observed that adults tend to buy cooked foods or raw ingredients to cook for their family, while adolescents generally depend on their parents for meals and prefer to buy snacks from grocery stores. Our results indicated a trend of young adults' DailyWalk being more associated with 'cooked foods' (e.g. snack/breakfast street vending and restaurant), while older adults' DailyWalk was more associated with 'raw ingredient' foods (e.g. fruit/vegetable street vending, market and supermarket). This reveals that higher consumption outlets with cooked/ready-to-eat foods are likely to increase younger adults' PA, while basic types of food outlet with lower consumption levels potentially enhance older adults' PA, in line with the findings from another recent study [15]. In future, research exploring the associations of PA with consumption levels of food outlets should also include age-related differences, particularly in small Chinese cities.

\section{Food environment diversity}

Mixed-use development is a key environmental factor in increasing PA [1, 7]; therefore, we hypothesised that combining the seven food amenities together could impact on people's DailyWalk. Following the same analysis [8], our results clearly showed that a higher level of diversity of food outlets in a neighbourhood was strongly associated with a longer DailyWalk. This demonstrates that if residents in small Chinese cities lived in neighbourhoods containing a variety of food outlets, they would be more physically active in their daily lives. Furthermore, apart from café/tea house, the occurrence of the other six food outlets within walking distance from home was high, suggesting that residents subjectively perceived a high availability of food outlets in their current neighbourhood. Thus, providing local food outlets is not a critical issue in small Chinese cities, compared with developed countries $[12,20]$. Additional research is needed to examine the impact of different combinations of individual food outlet on PA, as there might be an 'optimal' combination that is more likely to increase walking duration in Chinese neighbourhoods.

\section{Street vending}


During the survey, some participants mentioned that the mobility of street vendors had the potential to temporarily transform the place into an uncertain space in flux. Aside from the low prices, people said that they frequently visited these street spaces in order to see something new or to chat with vendors. For example, one participant visited the street vending area to see whether there were any new vendors selling new kinds of fruit (e.g. grapes, which were in season during the survey period). Another potential mechanism between street vending and increased DailyWalk might be in relation to the enhancement of social connectedness on a daily basis, namely, seeing fresh actors and chatting with vendors might contribute to a change in mood and potentially help restore people's mental well-being [13]. Future research should examine transport-related PA in tandem with an examination of the health benefits of street vending.

\section{Advantages and limitations}

Some caution is required in interpreting the results of this study. The cross-sectional approach cannot confirm causality between residential food outlets and DailyWalk. Perceived walking duration might differ from the actual walking time measured by objective pedometers. For example, compared with younger people, older people are likely to perceive a longer walk for the same distance [17, 19]. However, this potential deviation has been reduced by our exclusion of people over the age of 59 . Given the inclusion of only a small number of food outlet typologies, an exploration of the potential health benefits of other food outlets such as bars and food delivery providers is warranted in future studies. In addition to studying only static food outlets such as cafés and restaurants, the physical health benefits of the mobile food outlets such as street vending need to be separately studied.

Nevertheless, this study has its advantages, in that it expands existing knowledge of neighbourhood walkability by providing empirical evidence of the fine-grained relationship between food outlets and DailyWalk, in small Chinese cities, where a majority of the Chinese population live. A few studies have shown that type of commercial food destination is differently correlated with physical activity/walking across different age groups [12]. Our study not only provides detailed evidence of how the proximity of neighbourhood food destinations increases PA; it also explores nuanced associations for younger and older adults. Although such age-related differences were not particularly remarkable, a latent trend related to cooked foods and raw ingredients was uncovered. Overall, this novel study reveals a series of potential research directions that deserve more detailed examination in the future.

\section{Conclusions}

Although participants in this study reported high availability of food outlets in their neighbourhoods, urban planners and designers could help to facilitate a greater variety of food-based amenities within residential neighbourhoods, including fruit/vegetable and snack/breakfast street vending. Some food outlets with a recreational purpose and high consumption levels need to be carefully considered because they might engage mainly younger people or serve special demands, which exclude the common residents. Future research using longitudinal methods should further explore the associations between neighbourhood food outlets and PA by examining the roles of proximity, food outlet density and diversity in relation to walking 
behaviour and food consumption among specific age groups. Following the more complex discussions above, our key conclusions and recommendations are as follows:

- - Residential food outlets might be related to obesity or body mass index issues, but are positively associated with PA in small Chinese cities.

- - Street vending practices should be further facilitated and supported by Chinese city authorities, as they have been shown in this study to be a potential built environment construct that enhances walking duration. How different categories of street vending are associated with PA or other health outcomes could be a key area for future research.

- For future research, scholars not only need to take age groups with different consumption levels into account but should also explore the hierarchy of different food outlet typologies in relation to local culture and society. An exploration of the impact of location and different combinations of food outlet in a residential neighbourhood could also be explored.

- - There needs to be a differentiation between necessary and recreational food amenities in local neighbourhoods, because the two typologies are likely to play different roles in increasing PA.

\section{Declarations}

\section{Ethics approval and consent to participate}

This research was approved by the ECA Ethics Committee at the University of Edinburgh (No. 06032017). These procedures have been developed in line with recommendations from the College of Arts, Humanities and Social Sciences Ethics Committee and Research Ethics Framework (University of Edinburgh), and are undertaken in connection with any considerations that may be required by external collaborators, funders, or other external bodies. All participants in our study were anonymous and recruited from public streets.

\section{Consent for publication}

Not applicable.

\section{Availability of data and materials}

The data that support the findings of this study are available from EThOS (DOI:10.7488/era/255), but restrictions apply to the availability of these data until 02.07 .2021 , and so are not publicly available yet.

\section{Competing interests}

The authors declare that they have no competing interests.

\section{Funding}

This research was supported by the China Scholarship Council, grant number 201608060149; China Ministry of Housing and Urban-Rural Development, grant number K22018130; Tweedie Exploration 
Fellowship; Henry Lester Trust and; Great Britain-China Educational Trust.

\section{Author Contributions}

Z.S. acquired funding, conceived and designed the study, collected the data and prepared the original manuscript; X.Z. performed data analysis and edited the manuscript; S.B. and I.S. reviewed the methodology; S.B., I.S. and L.W. critically edited the manuscript. All authors have read and agreed to the published version of the manuscript.

\section{Acknowledgments}

We would like to express our gratitude to the volunteers from Yuncheng University and Suihua Urban Planning Department who supported the questionnaire data collection. We would like to thank Catharine Ward-Thompson, Mathew White, Peter Aspinall, Francisca Lima, Ka Yan Lai and Chengrun Li who discussed and helped this study in different stages. Finally, we would like to thank Edinburgh School of Architecture and Landscape Architecture and OPENspace Research Centre at the University of Edinburgh for facilitating this research.

\section{Abbreviations}

PA: physical activity

DailyWalk: perceived daily walking duration

ECA: Edinburgh College of Art

OR: odds ratio

95\%Cl: 95\% confidence intervals

\section{References}

1. Giles-Corti B, Vernez-Moudon A, Reis R, Turrell G, Dannenberg AL, Badland H, et al. City planning and population health: a global challenge. Lancet. 2016;388(10062):2912-24.

2. Speck J. Walkable city how downtown can save American, one step at a time. New York: North Point Press; 2012.

3. Gehl J. Cities for people. Washington: Washington : Island Press; 2010.

4. Biddle SJ, Asare M. Physical activity and mental health in children and adolescents: a review of reviews. Br J Sports Med. 2011;45(11):886-95.

5. Adkins A, Makarewicz C, Scanze M, Ingram M, Luhr G. Contextualizing Walkability: Do Relationships Between Built Environments and Walking Vary by Socioeconomic Context? J Am Plann Assoc. 2017;83(3):296-314. 
6. Duncan MJ, Winkler E, Sugiyama T, Cerin E, duToit L, Leslie E, et al. Relationships of Land Use Mix with Walking for Transport: Do Land Uses and Geographical Scale Matter? J Urban Health. 2010;87(5):782-95.

7. Sugiyama T, Cerin E, Owen N, Oyeyemi AL, Conway TL, Van Dyck D, et al. Perceived neighbourhood environmental attributes associated with adults recreational walking: IPEN Adult study in 12 countries. Health Place. 2014;28:22-30.

8. Saelens BE, Sallis JF, Black JB, Chen D. Measuring perceived neighborhood environment factors related to walking/cycling. Ann Behav Med. 2002;24:139.

9. Saelens BE, Handy SL. Built environment correlates of walking: a review. Med Sci Sports Exerc. 2008;40(7 Suppl):S550-66.

10. Day K. Built environmental correlates of physical activity in China: A review. Prev Med Rep. 2016;3:303-16.

11. Rosenberg D, Ding D, Sallis JF, Kerr J, Norman GJ, Durant N, et al. Neighborhood Environment Walkability Scale for Youth (NEWS-Y): reliability and relationship with physical activity. Prev Med. 2009;49(2-3):213-8.

12. Johnson AM, Dooley EE, Ganzar LA, Jovanovic CE, Janda KM, Salvo D. Neighborhood Food Environment and Physical Activity Among U.S. Adolescents. American journal of preventive medicine. 2019;57(1):24-31.

13. Kaplan S. The Restorative Benefits of Nature - toward an Integrative Framework. J Environ Psychol. 1995;15(3):169-82.

14. Rioux L, Werner CM, Mokounkolo R, Brown BB. Walking in two French neighborhoods: A study of how park numbers and locations relate to everyday walking. J Environ Psychol. 2016;48:169-84.

15. Sun Z, Lai KY, Bell S, Scott I, Zhang X. Exploring the Associations of Walking Behavior with Neighborhood Environments by Different Life Stages: A Cross-Sectional Study in a Smaller Chinese City. International Journal of Environmental Research and Public Health. 2020;17(1).

16. Ding D, Gebel K. Built environment, physical activity, and obesity: What have we learned from reviewing the literature? Health \& Place. 2012;18(1):100-5.

17. Kaczynski AT, Potwarka LR, Smale BJA, Havitz ME. Association of Parkland Proximity with Neighborhood and Park-based Physical Activity: Variations by Gender and Age. Leisure Sciences. 2009;31(2):174-91.

18. Curl A, Thompson CW, Aspinall P. The effectiveness of 'shared space' residential street interventions on self-reported activity levels and quality of life for older people. Landsc Urban Plan. 2015;139:11725.

19. Brookfield K, Ward Thompson C, Scott I. The Uncommon Impact of Common Environmental Details on Walking in Older Adults. Int J Environ Res Public Health. 2017;14(2):190.

20. Tani Y, Suzuki N, Fujiwara T, Hanazato M, Kondo N, Miyaguni Y, et al. Neighborhood food environment and mortality among older Japanese adults: results from the JAGES cohort study. Int J Behav Nutr Phys Act. 2018;15(1):1-12. 
21. Cobb LK, Appel LJ, Franco M, Jones-Smith JC, Nur A, Anderson CAM. The relationship of the local food environment with obesity: A systematic review of methods, study quality, and results. Obesity. 2015;23(7):1331-44.

22. Walker BB, Shashank A, Gasevic D, Schuurman N, Poirier P, Teo K, et al. The Local Food Environment and Obesity: Evidence from Three Cities. Obesity. 2020;28(1):40-5.

23. Ferreira I, van der Horst K, Wendel-Vos W, Kremers S, van Lenthe FJ, Brug J. Environmental correlates of physical activity in youth - a review and update. Obes Rev. 2007;8(2):129-54.

24. Brug J. Determinants of healthy eating: motivation, abilities and environmental opportunities. Fam Pract. 2008;25 Suppl 1(S1):i50-5.

25. Brug J, van Lenthe FJ, Kremers SPJ. Revisiting Kurt Lewin: How to gain insight into environmental correlates of obesogenic behaviors? American Journal of Preventive Medicine. 2006;31:525-9.

26. Giskes K, van Lenthe F, Avendano-Pabon M, Brug J. A systematic review of environmental factors and obesogenic dietary intakes among adults: are we getting closer to understanding obesogenic environments? Obes Rev. 2011;12(5):e95-e106.

27. Story M, Kaphingst KM, Robinson-O'Brien R, Glanz K. Creating healthy food and eating environments: policy and environmental approaches. Annu Rev Public Health. 2008;29(1):253-72.

28. Volpe R, Okrent AM, United S, Department of A, Economic Research S. Assessing the healthfulness of consumers' grocery purchases.2012.

29. Lake AA. Neighbourhood food environments: food choice, foodscapes and planning for health. Proc Nutr Soc. 2018;77(3):239-46.

30. Hearst MO, Pasch KE, Laska MN. Urban v. suburban perceptions of the neighbourhood food environment as correlates of adolescent food purchasing. Public Health Nutr. 2012;15(2):299-306.

31. Morland KB, Evenson KR. Obesity prevalence and the local food environment. Health Place. 2009;15(2):491-5.

32. Sevtsuk A. Location and Agglomeration: The Distribution of Retail and Food Businesses in Dense Urban Environments. J Plan Educ Res. 2014;34(4):374-93.

33. Cerin E, Lee KY, Barnett A, Sit CH, Cheung MC, Chan WM, et al. Walking for transportation in Hong Kong Chinese urban elders: a cross-sectional study on what destinations matter and when. Int $\mathrm{J}$ Behav Nutr Phys Act. 2013;10:78.

34. Lu Y, Xiao Y, Ye Y. Urban density, diversity and design: Is more always better for walking? A study from Hong Kong. Prev Med. 2017;103S:S99-S103.

35. Liu J, Zhou J, Xiao L, Yang L. Effects of the built environment on pedestrian communing to work and

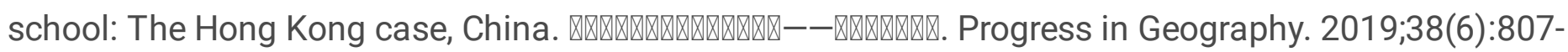
17.

36. Jia YN, Usagawa T, Fu H. The Association between Walking and Perceived Environment in Chinese Community Residents: A Cross-Sectional Study. Plos One. 2014;9(2).

37. Liu Z, Liu SH, Qi W, Jin HR. Urban sprawl among Chinese cities of different population sizes. Habitat International. 2018;79:89-98. 
38. Sun Z, Bell S, Scott I, Qian J. Everyday use of urban street spaces: the spatio-temporal relations between pedestrians and street vendors: a case study in Yuncheng, China. Landscape research. 2020;45(3):292-309.

39. Koohsari MJ, Sugiyama T, Sahlqvist S, Mavoa S, Hadgraft N, Owen N. Neighborhood environmental attributes and adults' sedentary behaviors: Review and research agenda. Prev Med. 2015;77:141-9.

40. Liu K. Street vendors in Chinese cities since economic reform: a case study of Guangzhou. [PhD Thesis]: University of Hong Kong; 2013.

41. National Bureau of Statistics of China. Sixth National Population Census of the People's Republic of China. 2010.

42. China Business Network. Ranking of Chinese Cities Based on Commercial Attraction in 2017. Shanghai; China Business Network Co., Ltd: New First-Tier Cities Research Institute; 2017.

43. Cerin E, Saelens BE, Sallis JF, Frank LD. Neighborhood Environment Walkability Scale: validity and development of a short form. Med Sci Sports Exerc. 2006;38(9):1682-91.

44. Flock R, Breitung W. Migrant Street Vendors in Urban China and the Social Production of Public Space. Popul Space Place. 2016;22(2):158-69.

45. Sun Z, Bell S, Scott I. How Does Street Vending Contribute to Walkability? A report on a study in Yuncheng, China. E-BPJ Environment-Behaviour Proceedings Journal. 2016;1(4):203-13.

46. Fan P, Park H, Wan G, Xu L, Xie Y, Liu Y, et al. Walkability in urban landscapes: a comparative study of four large cities in China. Landscape Ecology. 2017;33(2):323-40.

47. Barnett DW, Barnett A, Nathan A, Van Cauwenberg J, Cerin E, Council on E, et al. Built environmental correlates of older adults' total physical activity and walking: a systematic review and meta-analysis. Int J Behav Nutr Phys Act. 2017;14(1):103.

48. Van den Broeck J, Cunningham SA, Eeckels R, Herbst K. Data cleaning: detecting, diagnosing, and editing data abnormalities. PLoS Med. 2005;2(10):e267.

49. Maria AR, Cristina E, Miriam B, Eulogio P, Jes`s M, JosÈ AQ, et al. Self-reported daily walking time in COPD: relationship with relevant clinical and functional characteristics. Int $\mathrm{J}$ Chron Obstruct Pulmon Dis. 2017:1173-81.

50. Lin SN, Gaubatz P. Socio-spatial segregation in China and migrants' everyday life experiences: the case of Wenzhou. Urban Geogr. 2017;38(7):1019-38.

\section{Supplementary Files}

This is a list of supplementary files associated with this preprint. Click to download.

- SupplmentaryTables.docx

- STROBEchecklistcrosssectional.doc 